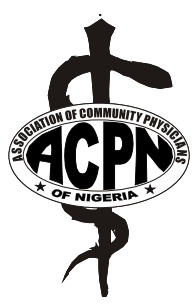

\title{
Sero-prevalence of hepatitis $B$ surface antigen among primary school pupils in rural Hawal valley, Borno State, Nigeria
}

\author{
DN Bukbuk, ${ }^{1}$ AP Bassi, ${ }^{2}$ and ZM Mangoro ${ }^{2}$
}

\begin{abstract}
${ }^{1}$ Departments of Immunology and ${ }^{2}$ Community Medicine, University of Maiduguri Teaching Hospital, P.M.B. 1414 and University of Maiduguri, P.M.B. 1069, Borno state, Nigeria.
\end{abstract}

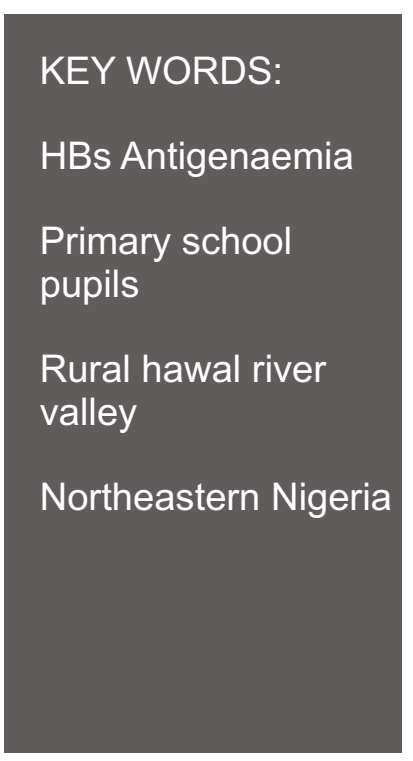

\section{Abstract}

Background and objective: Hepatitis $B$ virus infection is a major public health problem worldwide and in Africa. In the northeastern part of Nigeria. Information on the prevalence of HBV infection in rural communities is scarce. This study was carried out to determine the sero-prevalence of hepatitis B surface antigen amongst primary school pupils in a rural setting in northeastern Nigeria.

Methods: Hepatitis B surface antigen was tested for in 150 apparently healthy children in two primary schools in two rural communities situated in the Hawal valley area in Borno State, North East zone of Nigeria using an Enzyme Linked Immunosorbent Assay technique.

Results: The overall sero-positivity of Hepatitis B surface antigen (HBsAg) in the pupils was $44.7 \%$ (95\% C.I: 36.6 53.0). The prevalence of HBsAg was found to increase with age, rising from $40.6 \%$ in children aged $10-11$ years to $75 \%$ in children aged above 13 years. The sero-prevalence is $(47.2 \%,(95 \%$ C.I: 37.5 57.1) among males while among the females it was slightly lower $38.1 \%$ (95 C.I: $23.654 .4 \%$ ). The differences in the HbsAg sero-prevalence by age, sex and location were not statistically significant.

Conclusion: The high prevalence of HBsAg in the two primary school children provides evidence for an urgent mass immunization for children on entry to the schools.

\section{Introduction}

Hepatitis $B$ is one of the most common infectious diseases in the world and a major public health problem. It has been estimated that 350 million people worldwide are chronic hepatitis B virus (HBV) carriers. ${ }^{1}$ The prevalence of chronic HBV infection shows wide regional variation; ranging from high rates of greater than $8 \%$, found in, Africa, Asia and the Western Pacific to intermediate rates of 2-7\% in Southern and Eastern Europe to low rates of less than 2\%, in Western Europe, North America and Australia. ${ }^{1,2}$ The predominant routes of transmission vary according to the endemicity of the HBV infection. In areas of high endemicity, perinatal transmission is the main route of transmission, whereas in areas of low endemicity, sexual contact amongst high-risk adults is predominant.

Hepatitis epidemiology in Africa and Asia has shown that China ranks one of the high endemicity regions with little success in the contol ${ }^{3}$. There is little documentation from Nigeria especially amongst school children; most countries in Africa have high HBV endemicity, with the exception of Tunisia and Morocco, which have intermediate endemicity and Zambia has borderline intermediate/high endemicity $4,5,6$

The consequences of infection are enormous; between one-quarter and one-third of people infected chronically with HBV are expected to develop progressive liver disease and annually, it causes one million deaths globally. Therapeutic intervention is the only option for those with established chronic HBV-associated liver disease. Lamivudine, a nucleoside analogue, is the first effective, and well-tolerated, oral treatment for chronic hepatitis $B$. However, mass vaccination programs have begun to control the spread of HBV infection.

This study was carried out to ascertain the prevalence of hepatitis B infection amongst the primary school pupils in the Hawal valley and to make recommendations to government on appropriate intervention.

\section{Methodology}

\section{The study area}

The study was conducted in Hawal valley where the agrarian population is stable. The study population was drawn from two communities, Ghung and Buma, located in the Hawal valley. The river Hawal forms part of the upper Benue river system, which lies in the southern 
Sudan savannah grassland in northeastern Nigeria. ${ }^{3}$ The primary schools, one each in Ghung and Burma, have an annual school enrolment rate of 234 and 256 , respectively.

\section{Methods}

The study design was a descriptive cross-sectional survey. The study population consisted of primary school pupils drawn from the two primary schools in Ghung and Buma communities.

\section{Population and sample size determination}

The annual school enrolment for all the arms of the pupils in the two communities was 490 . The number of pupils sampled was guided by the upper limit required to give $95 \%$ level of confidence at an expected prevalence of $17.7 \%$ considering that this area is endemic for hepatitis $B$ virus infection ${ }^{4}$ using the precise prevalence given by the formula (reference ); Sample Size $=n /(1-(n /$ population size), where $n=z^{*} z(P(1-P)) /\left(D^{*} D\right) ; n=$ number of pupils required in the survey, $Z=$ normal standard deviate $(1.96$ for an á of 0.05), $\mathrm{P}=$ proportion of individuals in the area with HBsAg (i.e. 17.7\%), and D=is the precision of the estimate or acceptable error(set at 0.05$)^{5}$. The sample size calculated was 142 and was rounded up to 150 .

A multistage sampling technique was adopted. In the first stage, two primary schools in the area were selected (Ghung and Buma) and in each school a list of the pupils by age was extracted from the class registers. A die was tossed and every fifth pupil was then selected from the register and the interview and venepuncture carried out. There were more pupils in the lower age groups compared to those in the higher age group. The relevant data was collected by the authors, the venepuncture and data analysis too.

\section{Data collection and serology}

Data collection was primarily an interview schedule, where the selected pupils were interviewed concerning history of blood transfusion and jaundice in the preceding month before venepuncture was carried out.

After obtaining informed consent of parents and head teacher of the children, venous blood were collected in screw-capped glass containers in the field and brought to the Immunology Department of the University of Maiduguri Teaching Hospital. The blood was centrifuged at 2, 500 rpm for $10 \mathrm{mins}$, and serum aspirated and stored at $20^{\circ} \mathrm{C}$ in a mechanical freezer until tested. Serologic testing of $\mathrm{HBsAg}$, an important marker of hepatitis B virus infectivity was by use of a commercial recombinant antigen-based enzyme immunoassay (Wellcozyme HBsAg EIA Kits, Murex Diagnostics, Dartford, England) according to methods described earlier ${ }^{4}$.

\section{Data analysis}

The data obtained were entered into Epilnfo6.04 database. ${ }^{5}$ All statistical analysis was performed using GraphPad in Stat for windows release 5 (GraphPad
GraphPad in Stat for windows release 5 (GraphPad Software, San Diego, California USA). Simple frequency tables were used for data presentation and associations between categorical variables assessed using $X^{2}$ test with level of signifance set at $p$-value less than or equal to 0.05 .

\section{Results}

One hundred and fifty school pupils made up of 73 (48.7\%) from Buma and 77 (51.3\%) from Ghung primary schools respectively, were studied (Table1). The study population was made up of $108(72 \%$ and $42(28 \%)$ females, giving male: female ratio of $3: 1$. The overall sero-prevalence of HBsAg among the pupils was 44.7 (95\% C.I: 36.6 53.0) (Table 3). The distribution of HBsAg by age and sex in the two schools is shown in Table 2. A higher proportion of males (47.3, 95\% C.I: 37.5 57.1) were found to be seropositive compared to females (38.1, 95\% C.I: 23.654 .4 ) However, the difference was not statistically significant $(\mathrm{p}$ $\left(\mathbf{X}^{2}\right)=0.4084$.

Hepatitis B virus antigenaemia in both schools were similarly high, $46 \%$ (95\% C.I: 34.858 .6 ) in Burma and 42.9\% (95\% C.I: 31.654 .6 ) with no significant differences observed in the two schools $p\left[\mathbf{X}^{2}\right]=0.7691$. (Tables $2 \& 3$ ).

\begin{tabular}{llll}
\hline $\begin{array}{l}\text { Table 1: Demographic profile of primary school pupils in } \\
\text { Hawal Valley }\end{array}$ \\
\hline Variable & Buma & Ghung & Total \\
& $\mathrm{N}=73(48.7 \%)$ & $\mathrm{N}=77(51.3 \%)$ & $\mathrm{N}=150$ \\
\hline Age group (years) & & & \\
$10-11 \quad(\mathrm{~N}=101)$ & 53 & 48 & 101 \\
$12-13 \quad(\mathrm{~N}=45)$ & 20 & 25 & 45 \\
$13+\quad(\mathrm{N}=4)$ & 0 & 4 & 4 \\
Mean age (SD) & $10.91(0.82)$ & $11.2(1.12)$ & \\
$95 \% \quad \mathrm{C.I}$ & 10.711 .1 & 11 & 11.5 \\
Gender & & & \\
Male & 58 & 50 & 108 \\
Female & 15 & 27 & 042 \\
\hline
\end{tabular}

\section{Discussion}

This study showed that the girl - child is not favoured in the access to primary education in this area. In addition, the age and class increase with the drop out rate (Table 1).

This sero-prevalence survey in rural northeastern Nigeria showed an overall high prevalence of 44.7 per cent amongst primary school pupils. The prevalence increases with increasing age of the pupils. The antigenaemia is also higher amongst the male (47.2 percent) than female (38.1 percent). This is expected as being male is known to increase the risk of serum hepatitis infection. ${ }^{8}$

Nigeria and Bangladesh have scarce information on hepatitis B infections that will support an effective intervention program; however, there is emerging evidence of increasing prevalence with age of the hepatitis $B$ surface antigen. The prevalence of hepatitis $B$ amongst primary school children aged 10-14 years was 5.9 percent

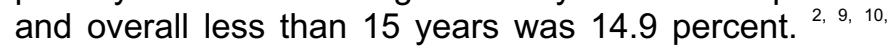




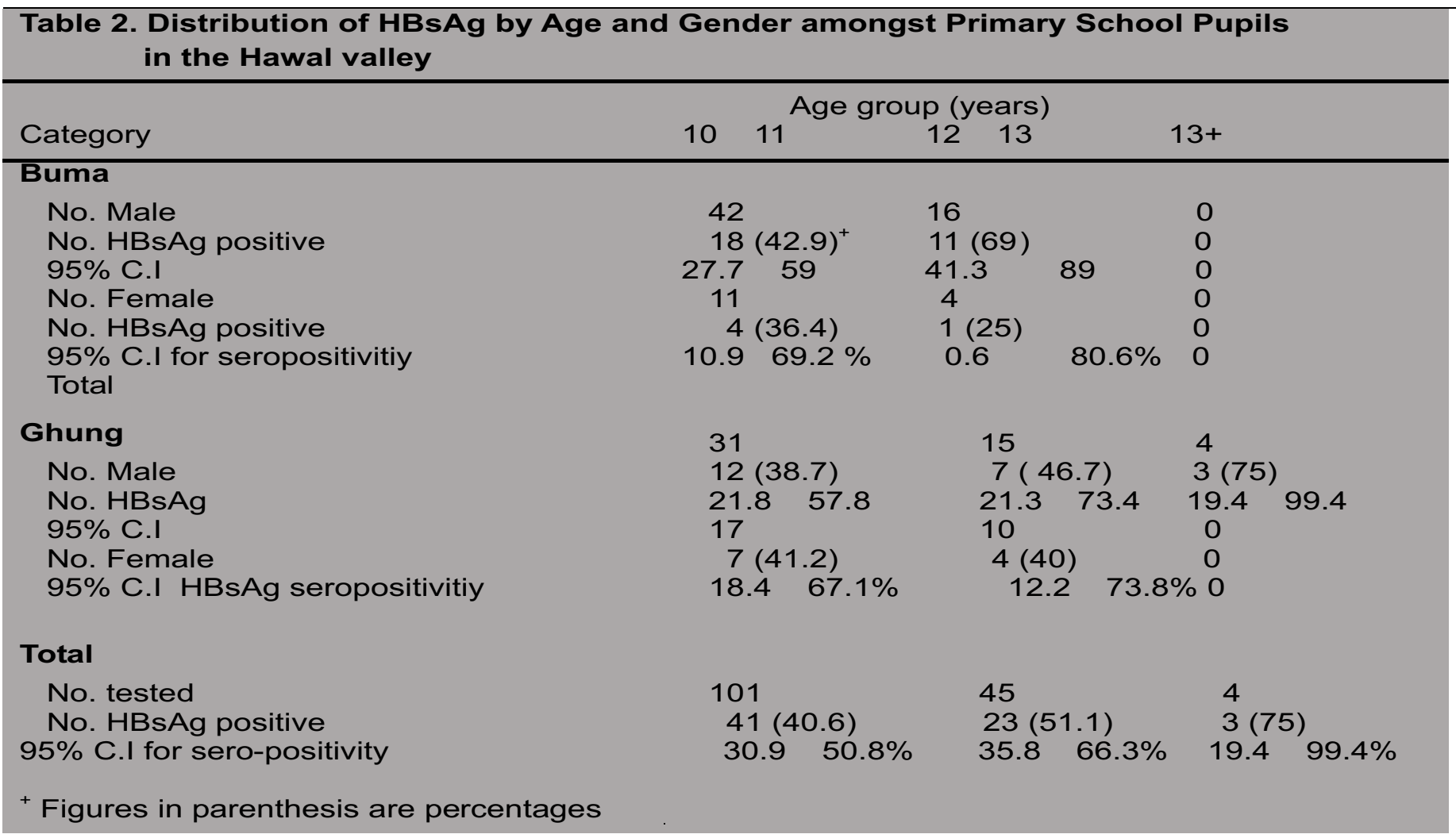

Taiwan has also greatly reduced HBV infection rate through its vaccination programme taking into account the mode of transmission of HBV, the healthcare infrastructure to deliver vaccination. In addition, the socio-economic and political factors in the individual country must be determined. ${ }^{11}$ Greece is in intermediate endemicity for hepatitis B and low endemicity for hepatitis $C$ with a downward trend during the last years. This study also showed that male sex was an important risk factor in the
Rural areas as in previous studies conducted in Greece. ${ }^{8}$ The overall prevalence in rural Mexico was $6.6 \%$ for antibody to hepatitis B core antigen and the prevalence gradually increased with age up to the age of 40 years. ${ }^{12}$

Similar studies in Italy provided the template for routine EPI implementation introducing hepatitis $B$ in a cost effective manner and the global assessment of hepatitis B immunization has shown the reduction of the infection ${ }^{13}$. In

Table 3: Hepatitis B surface Antigenaemia by selected variables in school pupils in the Hawal valley

\begin{tabular}{|c|c|c|c|c|}
\hline \multirow{2}{*}{ Variable } & \multicolumn{2}{|c|}{ No. With } & \multicolumn{2}{|c|}{$p$-value } \\
\hline & No. Tested & $\mathrm{HBsAg}$ & $(\%)$ & {$\left[x^{2}\right.$ test] } \\
\hline \multicolumn{5}{|l|}{ Sex } \\
\hline Male & 108 & 51 & $(47.2)$ & \\
\hline Female & 42 & 16 & (38.1) & 0.4084 \\
\hline \multicolumn{5}{|l|}{ Age group } \\
\hline$<12$ & 101 & 41 & $(40.6)$ & \\
\hline $12 \quad 13$ & 45 & 23 & (51.1) & \\
\hline $13+$ & 4 & 3 & $(75.0)$ & 0.3215 \\
\hline \multicolumn{5}{|l|}{ School } \\
\hline Buma & 73 & 34 & $(46.6)$ & \\
\hline Ghung & 77 & 33 & $(42.9)$ & 0.7691 \\
\hline
\end{tabular}


Lucknow, India the universal immunization reduced the HBV carrier rate by 71 percent, and increased the number of years and quality-adjusted-life-year (QALY) lived by a birth-cohort by 0.173 years and 0.213 years respectively. ${ }^{14}$ Migliani et al (2000) ${ }^{15}$ in Madagascar showed the association between vertical and horizontal transmissions for the childhood as being high with an estimated prevalence rate for HBs antigen infection of 10 to 35 percent among children under less than 5-year-old. The results suggest that universal vaccination of infants in the first year of life and adolescents at 12 years of age has a greater efficacy on reducing the endemicity in the general population in comparison with selective vaccination. In this study, the prevalence of HBsAg was highest in the 13+ year old group $(3 / 4,75$ per cent), $12-13$ year old $(23 / 45,51$ per cent) and 10-11 year old (41/101, 40.6 per cent). Some studies conducted in Nigeria and Bangladesh corroborated the increasing prevalence with age and showed the overall prevalence to be less than 32 percent. ${ }^{2}$.

Hepatitis B surface antigen was found in these apparently healthy rural Nigerian children in the two primary schools of the areas Ghung and Buma along the Hawal River, northeastern Nigeria.

Ayoola et al (2003) in their study between 1995 and 1998 showed a decline in the prevalence of hepatitis $B$ particularly amongst children. This was associated to the effect of inclusion of Hep B vaccine in the routine schedule of immunization. Also in the report on the global overview of hepatitis B infant and adolescent immunization programmes, Vryheid and colleagues ${ }^{16}$ in 2000 reported that adopting universal immunization strategies have greatly reduced incidence and prevalence, and are costeffective for many countries, although some have difficulties in affording the vaccines ${ }^{16}$. Therefore, including hepatitis B vaccine into routine EPI and making it a pre requisite for admission into primary school may not only reduce the incidence of Hepatitis $B$ antigen carrier rate and chronic hepatitis $B$ virus infection but will also increase the utilization of health services including immunization in northeastern Nigeria. There is dire need to introduce hepatitis B vaccine particularly to the at-risk (5-14 year old) age group.

\section{Acknowledgements}

The authors acknowledge the Education Secretary, Hawal Local Government, Borno State, Mr. Jonathan Mshelia of the Department of Geography, University of Maiduguri and the village heads of Ghung and Buma for the cooperation accorded us throughout the period of study.

\section{References}

1. Maddrey WC. Hepatitis B-an important public health issue. Clin. Lab (2001). 47(1-2):51-5

2. Zaki H, Darmstadt GL, Baten A, Ahsan CR, Saha SK. Seroepidemiology of hepatitis $B$ and delta virus infections in Bangladesh. (2003). Vaccine 14:17-23

3. Bradley AK. Effects of onchocerciasis on settlement in the Middle Hawal Valley, Nigeria, Trans Roy
Soc Trop Med Hyg 1976; 70 (3): 225229

4. Bukbuk DN and Udoh E. The relationship of blood groups and Hepatitis B virus surface antigen carrier state among blood donors in Maiduguri, Nigeria. Niger Med Pract. (1997). 33 (3/4): 35-37

5. Dean AG, Dean JA, Coulombier D, Brendel KA, Smith DC, Burton AH, Dicker RC, Sullivan K, Fagan RF, Arner TG. Epilnfo, version 6: a word processing, database, and statistics program for epidemiology on microcomputers. Centers for Disease Control and Prevention, Atlanta, Georgia, USA. 1995; Pp. 1-189

6. Yao GB. Importance of perinatal versus horizontal transmission of hepatitis B virus infection in China, Gut 1996. 38 Suppl. 2: S39 42

7. $\quad$ Andre F. Hepatitis B epidemiology in Asia, the Middle East and Africa. Vaccine. 2000; 18 Suppl. 1:S20-2

8. Gogos CA, Fouka KP, Nikiforidis G, Avgeridis K, Sakellaropoulos G, Bassaris H, Maniatis A, Skoutelis A. Prevalence of hepatitis $B$ and $C$ virus infection in the general population and selected groups in South-Western Greece. Eur. J Epidemiol. (2003). 18 (6):551-7

9. Onakewhor UE Offor FE Okonofua J. Maternal and neonatal sero-prevalence of hepatitis $B$ surface antigen (HBsAg) in Benin City, Nigeria. J Obstet. Gynaecol. 2001. 21(6): 583-586

10. Sirisena ND, Njoku MO, Idoko JA, Isamade E, Barau C, Jelpe D, Zamani A, Otowo S. Carriage rate of hepatitis-B surface antigen (HBsAg) in an urban community in Jos, Plateau State, Nigeria. Niger Postgrad. Med J. (2002) 9(1):7-10

11. Ayoola AE, Tobaigy MS, Gadour MO, Ahmad BS, Hamza MK, Ageel AM. The decline of hepatitis B viral infection in South-Western Saudi Arabia. Saudi Med J. 2003; 24(9): 991-5

12. Cisneros-Castolo M, Hernandez-Ruiz L, IbarraRobles IE, Fernandez-Garate RH, Escobedo-De La Pena J. Prevalence of hepatitis $B$ virus infection and related risk factors in a rural community of Mexico. Am J Trop Med Hyg $2001 ; 65(6): 759-63$

13. Da Villa G, Picciottoc L, Elia S, Peluso F, Montanaro F, Maisto T. Hepatitis B vaccination: universal vaccination of newborn babies and children at 12 years of age versus high-risk groups. A comparison in the field. Vaccine. 2003; 13 (13): 1240-3

14. Aggarwal R, Ghoshal UC, Naik SR. Assessment of cost-effectiveness of universal hepatitis $B$ immunization in a low-income country with intermediate endemicity using a Markov model. J Hepatol. 2003; 38(2):215-22

15. Vryheid RE, Kane MA, Muller N, Schatz GC, Bezabeh S. Infant and adolescent hepatitis B immunization up to 1999: a global overview: Vaccine 2000; 19 (9-10): 1026-37 